\title{
Modified Technique for Retrograde Cerebral Perfusion during Hemiarch Aortic Replacement
}

\author{
Nicholas T. Kouchoukos, MD ${ }^{1}$ Marc Haynes, BSN, RN ${ }^{1}$ Sarah Hester, RN ${ }^{1}$ \\ Catherine F. Castner, BSN, RN ${ }^{1}$ \\ ${ }^{1}$ Division of Cardiovascular and Thoracic Surgery, Missouri Baptist \\ Address for correspondence Nicholas T. Kouchoukos, MD, Missouri \\ Medical Center, BJC Healthcare, St. Louis, Missouri \\ Baptist Medical Center, 3023 North Ballas Road, Suite 150D, St. Louis, \\ MO 63131 (e-mail: ntkouch@aol.com).
} Aorta (Stamford) 2021;9:100-105.

\begin{abstract}
Background Uncertainty remains regarding the optimal method of brain protection for procedures that require repair or replacement of the aortic arch. We examined the early outcomes of a technique for brain protection in patients undergoing partial aortic arch (hemiarch) replacement that involves deep hypothermic circulatory arrest (DHCA) and retrograde cerebral perfusion (RCP) of cold blood from the superior vena cava toward the end of the arrest interval.

Methods During a recent 15-year interval, 520 patients underwent elective or urgent/emergent ascending aortic and hemiarch replacement as an isolated (47 patients) or combined (473 patients) procedure employing DHCA (mean nasopharyngeal temperature at circulatory arrest, $17.1^{\circ} \mathrm{C}$ and mean duration, 19.3 minutes) supplemented with RCP of cold blood from the superior vena cava toward the end of the arrest interval (mean, 6.7 minutes). The mean age of the patients was 59.5 years, and $65 \%$ were male.

Results The in-hospital and 30-day mortality rates were $1.2 \%$ (six patients). Seven patients $(1.4 \%)$ sustained a stroke and 19 patients $(3.7 \%)$ had transient neurologic dysfunction that completely resolved by the time of hospital discharge. Four patients

\section{Keywords}

- brain protection

- hemiarch replacement

- retrograde cerebral perfusion $(0.77 \%)$ developed postoperative renal failure requiring dialysis. Twenty-one patients (4\%) required ventilator support for $>48$ hours and five patients $(0.96 \%)$ required a tracheostomy. The median hospital length of stay was 6 days.

Conclusion DHCA with a brief interval of RCP is a safe and effective technique for brain protection during hemiarch aortic replacement. $R C P$ reduces the duration of brain ischemia and permits removal of particulate matter and air from the arterial circulation.
\end{abstract}

\section{Introduction}

The optimal method of brain protection for procedures that require repair or replacement of the aortic arch has not been clearly established. For patients who require total aortic arch replacement, often in combination with procedures on the ascending or descending thoracic aorta, there is emerging consensus that some form of brain perfusion is advisable during the interval of circulatory arrest which often exceeds

received

July 17,2020

accepted after revision

November 15, 2020

published online

October 12, 2021
30 to 40 minutes, to prevent neurologic injury. ${ }^{1,2}$ For patients who require partial replacement of the arch that does not involve the origins of the brachiocephalic arteries (hemiarch procedure) and generally involves shorter intervals of brain ischemia, the options for brain protection include deep hypothermic circulatory arrest (DHCA), retrograde cerebral perfusion (RCP) of cold blood into the superior vena cava in combination with DHCA, occlusion of the brachiocephalic arteries and perfusion of the brain through the right axillary

\section{(c) 2021. The Author(s)}

This is an open access article published by Thieme under the terms of the Creative Commons Attribution License, permitting unrestricted use, distribution, and reproduction so long as the original work is properly cited. (https://creativecommons.org/licenses/by/4.0/)

Thieme Medical Publishers, Inc., 333 Seventh Avenue, 18th Floor, New York, NY 10001, USA 
or innominate artery, and direct antegrade cerebral perfusion (ACP) of two or all three brachiocephalic arteries. The latter two techniques have been used in combination with deep or moderate hypothermia.

In 1994, we described a technique for brain protection during operations involving the aortic arch that utilizes DHCA and retrograde perfusion of the brain with cold, oxygenated blood from the superior vena caval cannula near the end of the interval of HCA as an adjunctive measure for brain protection. ${ }^{3}$ In this report, we present our experience with this technique in patients who underwent hemiarch replacement over a recent 15 -year interval.

\section{Materials and Methods}

Between January 2001 and December 2015, 520 patients underwent elective or urgent/emergent ascending aortic and hemiarch replacement as an isolated or combined procedure employing an interval of DHCA supplemented with retrograde brain perfusion of cold blood from the superior vena cava toward the end of the arrest interval. The rationale for the retrograde blood perfusion was to reduce the interval of brain ischemia and to remove particulate matter (thrombus, calcium, and atheromatous debris) and air from the arterial circulation. $^{3}$ During the study interval, no other technique for brain protection was utilized for patients undergoing hemiarch replacement. The mean age of the patients was $59.5 \pm 13.8$ years and 338 (65\%) were men. One hundred and forty-eight patients (28.5\%) were 70 years of age or older, and 23 patients $(4.4 \%)$ were 80 years of age or older. Data were analyzed retrospectively from a prospectively maintained database. Thirty-day follow-up was available for all 520 patients. ${ }^{4}$ The study was reviewed by the Institutional Review Board of the Missouri Baptist Medical Center and was exempted from board approval.

The principal indications for operation are shown in -Table 1. Four hundred and nineteen patients (80.6\%) had either aortic regurgitation or aortic stenosis as the indication for operation and had associated aneurysmal enlargement of the ascending aorta and proximal aortic arch. Ascending aortic and proximal aortic arch enlargement

Table 1 Principal indications for operation

\begin{tabular}{|l|l|l|}
\hline Indication & No. of patients & $\%$ \\
\hline Aortic valve disease: & & \\
\hline Regurgitation & 286 & 55.0 \\
\hline Stenosis & 133 & 25.6 \\
\hline $\begin{array}{l}\text { Ascending aortic and proximal } \\
\text { aortic arch disease: }\end{array}$ & & \\
\hline Aneurysm & 74 & 14.2 \\
\hline Atherosclerosis & 11 & 2.1 \\
\hline Acute dissection & 7 & 1.4 \\
\hline Chronic dissection & 9 & 1.7 \\
\hline Total & 520 & 100 \\
\hline
\end{tabular}

was the indication in 74 patients, 11 patients had severe atherosclerosis of the aortic segment, 7 patients had acute Type A aortic dissection, and 9 patients had chronic Type A aortic dissection with aneurysm formation. One hundred and two patients (19.6\%) had undergone a previous cardiac or ascending aortic procedure and 11 patients $(2.1 \%)$ had undergone two or more procedures. The procedures performed on the aortic valve are shown in - Table 2. Additional procedures that were performed concomitantly in 178 patients $(34.3 \%)$ are shown in - Table 3. Fifty-two of the 101 patients with aneurysm or other ascending aortic disease as the principal indication for operation required an additional procedure.

\section{Operative Technique}

After a full or partial median sternotomy incision, either the ascending aorta, the right axillary artery or a femoral artery was cannulated ( - Table 4 ). The vena cavae were cannulated separately. If cannulation through the right atrial wall was not possible, a long multistage catheter was inserted through a femoral vein with the tip positioned in the superior vena cava. After establishing cardiopulmonary bypass (CPB), cooling was initiated, the left heart was vented, and a cannula was inserted into the coronary sinus for delivery of cold blood cardioplegic solution. During cooling, the head was packed in ice, electroencephalographic and cerebral oxygen saturation monitoring were implemented, and intravenous methylprednisolone $(7-10 \mathrm{mg} / \mathrm{kg}$ ) was administered. After occlusion of the aorta, cardioplegic solution was administered into the coronary sinus at every 12 to 15 minutes. If the

Table 2 Procedures on the aortic valve ${ }^{a}$

\begin{tabular}{|l|l|l|}
\hline Condition & No. of patients & $\%$ \\
\hline Aortic root replacement: & 202 & 45.9 \\
\hline $\begin{array}{l}\text { Mechanical } \\
\text { valve + graft }\end{array}$ & 114 & \\
\hline Bioprosthetic valve: & & \\
\hline Stentless root graft & 83 & \\
\hline Valve + graft & 5 & 32.7 \\
\hline Aortic valve: & 144 & \\
\hline Pericardial valve & 94 & 13.8 \\
\hline Mechanical valve & 50 & \\
\hline Valve sparing procedure: & 61 & \\
\hline Commissural aortoplasty & 26 & 4.6 \\
\hline David procedure & 24 & 3.0 \\
\hline Yacoub's procedure & 7 & 100 \\
\hline Leaflet repair & 4 & \\
\hline $\begin{array}{l}\text { Allograft root } \\
\text { replacement }\end{array}$ & 20 & \\
\hline Ross procedure & 13 & \\
\hline Total & 440 & \\
\hline
\end{tabular}

${ }^{a} 21$ patients with aneurysm as the principal indication for operation had a procedure on the aortic valve or the aortic root. 
102 Modified Retrograde Cerebral Perfusion for Hemiarch Replacement Kouchoukos et al.

Table 3 Additional procedures in 178 patients $^{\mathrm{a}}$

\begin{tabular}{|l|l|l|}
\hline Procedure & No. of procedures & $\%$ \\
\hline $\begin{array}{l}\text { Coronary artery } \\
\text { bypass grafting: }\end{array}$ & 116 & 54.0 \\
\hline One & 49 & \\
\hline Two & 44 & 13.0 \\
\hline Three or more & 23 & \\
\hline $\begin{array}{l}\text { Polyester grafts to } \\
\text { coronary ostia: }\end{array}$ & 28 & 9.3 \\
\hline Left main coronary & 17 & 4.7 \\
\hline Right coronary & 1 & 100 \\
\hline Both & 10 & \\
\hline $\begin{array}{l}\text { Mitral valve repair/ } \\
\text { replacement }\end{array}$ & 20 & \\
\hline Maze procedure: & 10 & \\
\hline Left only & 7 & \\
\hline Bilateral & 3 & \\
\hline Tricuspid valve repair & 5 & \\
\hline Other: & 36 & \\
\hline $\begin{array}{l}\text { LVOT reconstruction } \\
\text { Closure patent } \\
\text { foramen ovale }\end{array}$ & 15 & \\
\hline $\begin{array}{l}\text { Ventricular } \\
\text { septal myectomy }\end{array}$ & 215 & \\
\hline $\begin{array}{l}\text { Ablation for } \\
\text { atrial flutter }\end{array}$ & 2 & \\
\hline $\begin{array}{l}\text { Permanent } \\
\text { pacemaker }\end{array}$ & 2 & \\
\hline $\begin{array}{l}\text { Pulmonary valve } \\
\text { replacement }\end{array}$ & 2 & \\
\hline Carotid & 2 & \\
\hline Total & 2 & \\
\hline
\end{tabular}

Abbreviation: LVOT, left ventricular outflow tract.

${ }^{a}$ Several patients had more than one procedure.

duration of aortic occlusion was prolonged to greater than 60 minutes, additional cardioplegic solution was infused directly into the coronary ostia or into grafts that had been attached to the coronary arteries, and topical cooling was added. When the electroencephalogram became isoelectric and the nasopharyngeal temperature reached $18^{\circ} \mathrm{C}$ or below, the patient was placed in a steep Trendelenburg's position and the superior vena caval cannula was clamped for 8 to 10 seconds to distend the upper venous system and to prevent suctioning of air into the brachiocephalic arteries when the aorta was opened. If a single venous cannula was used, it was occluded for a similar interval. Circulatory arrest was then established.

The aortic clamp and the ascending aortic cannula (if present), were removed. The aorta was opened and transected obliquely beneath the origins of the brachiocephalic
Table 4 Cardiopulmonary perfusion data

\begin{tabular}{|l|l|}
\hline Variable & Value \\
\hline Arterial cannulation site: & \\
\hline Ascending aorta & 425 \\
\hline Right axillary artery & 62 \\
\hline Femoral artery & 33 \\
\hline Duration (min): & \\
\hline Cardiopulmonary bypass & $130.8 \pm 43.2$ \\
\hline Aortic occlusion & $119.4 \pm 38.1$ \\
\hline Cooling & $27.7 \pm 6.0$ \\
\hline Circulatory arrest & $19.3 \pm 5.1$ \\
\hline Retrograde brain perfusion: & \\
\hline Minutes & $6.7 \pm 2.4$ \\
\hline Rate (mL/min) & $473.4 \pm 166.8$ \\
\hline Jugular venous pressure $(\mathrm{mm} \mathrm{Hg})$ & $24.1 \pm 7.2$ \\
\hline Temperature $\left({ }^{\circ} \mathrm{C}\right):$ & \\
\hline Lowest nasopharyngeal & $17.1 \pm 1.8$ \\
\hline Lowest bladder & $22.9 \pm 3.0$ \\
\hline
\end{tabular}

Note: Data presented as $n$ or as mean \pm standard deviation.

arteries which were not clamped or internally occluded. The length of aorta to be excised beneath the brachiocephalic arteries was determined by the extent of aneurysmal enlargement or atherosclerosis and could extend to the origin of the left subclavian artery. The opened aorta was sutured to an appropriately beveled collagen impregnated polyester graft (Hemashield, Maquet, Ratstatt, Germany). As this suture line was being completed, the superior vena cava was occluded with a tourniquet, and cold $\left(18-20^{\circ} \mathrm{C}\right)$ arterial blood was infused through the superior vena caval cannula for 5 to 8 minutes at a rate of 300 to $600 \mathrm{~mL} / \mathrm{min}$. The jugular venous pressure was not allowed to exceed 33 to $35 \mathrm{~mm} \mathrm{Hg}$. If a single venous cannula was used, a balloon-tipped cardioplegia cannula was inserted through a purse-string suture in the superior vena cava above a tourniquet, and the cold blood was infused through this catheter. When the suture line was completed and if a central aortic cannula was used, it was reinserted through a stab wound in the graft beneath the brachiocephalic arteries and secured with a purse-string suture. Air was evacuated from the descending thoracic aorta and the aortic graft by infusion of blood from the pump oxygenator through the aortic cannula or axillary or femoral artery. The aortic graft was occluded with a clamp just proximal to the origin of the innominate artery, CPB was reestablished, and rewarming was initiated. During rewarming, the necessary aortic root, aortic valve, and other procedures were performed. After completion of these procedures and evacuation of air from the heart, СPB was discontinued when the nasopharyngeal temperature reached $35^{\circ} \mathrm{C}$. The data related to cardiopulmonary perfusion are summarized in - Table 4. 


\section{Results}

\section{Early Mortality}

The in-hospital and 30-day mortality rates were $1.2 \%$ (six patients; - Table 5). Two patients died in the early postoperative period. A 52-year-old male with severe aortic regurgitation and massive cardiomegaly had dense inflammatory changes in the aortic root that precluded attachment of the left main coronary artery to the aortic graft at the time of aortic root replacement. He had placement of a saphenous vein graft from the aortic graft to the left main coronary artery and a subsequent vein graft to the left anterior descending coronary artery but succumbed from biventricular failure on the operative day. A 62-year-old male with critical aortic stenosis, previous mantle irradiation for Hodgkin's lymphoma and coronary artery bypass grafting, had replacement of his severely atherosclerotic aorta, the aortic root, and the mitral valve. He died on the first postoperative day of biventricular failure despite insertion of an intraaortic balloon pump and a temporary right-ventricular assist device. Three male patients, who were 72,75 , and 78 years of age, died on postoperative days 15,23 , and 36 , respectively, of multiple system organ failure. All three had extensive coronary artery disease that required bypass grafting, and two had severe atherosclerosis of the ascending aorta and arch that required graft replacement. The sixth patient, a 76year-old female died on the 25th postoperative day from ischemic bowel necrosis following repair of an acute Type A aortic dissection. The early mortality rate for the 372 patients under the age of 70 years was $0.5 \%$ (two patients), and for the 148 patients who were 70 years of age or older was $2.7 \%$ (four patients). The difference was not statistically significant ( $p=0.06$; Fischer's exact test statistic).

\section{Major Morbidity}

The prevalence of postoperative neurologic, renal, and pulmonary complications is shown in - Table 5 .

\section{Neurologic Injury}

Seven patients (1.4\%) sustained a stroke confirmed by computed tomographic (CT) or magnetic resonance (MR) imaging and by consultation from a neurologist. At the time of discharge, the neurologic deficits had resolved in four of the seven patients. Nineteen patients (3.7\%) developed transient neurologic dysfunction (-Table 5). Seizures occurred in three of these patients. CT imaging showed no evidence for brain injury in all three patients. The seizures resolved, and none of the patients required antiseizure medication. Delirium occurred in 4 of the 19 patients and CT imaging was negative for brain injury in all 4 of them. The remaining 12 patients had major confusion. CT imaging was obtained in six of these patients and no abnormalities were noted. All of the 19 patients had resolution of their neurologic symptoms by the time of hospital discharge.

\section{Renal Dysfunction}

Preoperative renal dysfunction, defined as a baseline serum creatinine level $>1.5 \mathrm{~mL} / \mathrm{dL}$, was present in 10 patients
Table 5 Postoperative mortality and major morbidity

\begin{tabular}{|l|l|l|}
\hline & No. of patients & $\%$ \\
\hline Early death & 6 & 1.2 \\
\hline Stroke & 7 & 1.4 \\
\hline Temporary neurologic dysfunction & 19 & 3.7 \\
\hline Seizures & 3 & \\
\hline Delirium & 4 & \\
\hline Confusion & 12 & \\
\hline Renal dysfunction & & \\
\hline Serum creatinine $>1.5 \times$ baseline & 23 & 4.4 \\
\hline Dialysis & \\
\hline Pulmonary dysfunction & 4 & 0.77 \\
\hline Ventilatory support $>48$ hours & 21 & \\
\hline Tracheostomy & & 4.0 \\
\hline
\end{tabular}

${ }^{a}$ Three patients successfully weaned, one died.

bour patients successfully weaned, one died.

(1.9\%). Postoperative hemodialysis was required in two of these patients. One patient died in the early postoperative period and the other patient required only temporary renal replacement therapy. Twenty-three patients (4.4\%) with normal renal function preoperatively developed postoperative dysfunction defined as an elevation of the serum creatinine $\geq 1.5$ times the baseline level ( - Table 5 ). Two of these patients required hemodialysis that was discontinued prior to hospital discharge.

\section{Pulmonary Complications}

Twenty-one patients (4\%) required ventilator support for more than 48 hours, and five patients $(0.96 \%)$ required tracheostomy and prolonged assisted ventilation. Four of the five patients were weaned from the ventilator and had removal of the tracheostomy tube before hospital discharge. The fifth patient died in the postoperative period (-Table 5).

\section{Other Morbidity}

Eighteen patients (3.5\%) required reoperation for bleeding (-Table 6). Delayed closure of the sternum was performed in 47 patients (9\%) in the first 24 to 48 hours postoperatively. Twenty-two of these patients had undergone a previous sternotomy. Intra-aortic balloon pumping was required in five patients. New onset atrial fibrillation occurred in 112 patients (21\%), and 14 patients $(2.7 \%)$ received a permanent pacemaker. These and other postoperative complications are summarized in - Table $\mathbf{6}$. The mean length of hospital stay was $7.5 \pm 4.9$ days (median, 6 days).

Data regarding intraoperative transfusion of allogeneic blood products were only available in the database for the 419 patients who were operated on after January, 2004. A total of 175 of these 419 patients (41.7\%) received no intraoperative transfusion of blood products. The blood products received by the remaining 244 patients are shown 
Table 6 Other postoperative morbidity

\begin{tabular}{|l|l|l|}
\hline Type of morbidity & $\begin{array}{l}\text { No. of } \\
\text { patients }\end{array}$ & $\%$ \\
\hline Reoperation for bleeding & 18 & 3.5 \\
\hline $\begin{array}{l}\text { Delayed closure of } \\
\text { sternal wound }\end{array}$ & 44 & 8.5 \\
\hline Intra-aortic balloon pump & 5 & 0.78 \\
\hline New atrial fibrillation & 112 & 21.5 \\
\hline Permanent pacemaker & 14 & 2.7 \\
\hline $\begin{array}{l}\text { Delayed drainage } \\
\text { of pericardial effusion }\end{array}$ & 20 & 3.9 \\
\hline Deep sternal wound infection & 5 & 0.98 \\
\hline
\end{tabular}

in - Table 7. One patient required transfusion of factor VIIa concentrate.

\section{Discussion}

Although there is general agreement that some form of brain perfusion (ACP or RCP) is advisable for patients undergoing total arch replacement, there is no consensus regarding the optimal method for brain protection for operations that require subtotal arch replacement. Kaneko and colleagues ${ }^{5}$ compared DHCA alone and combined with antegrade or retrograde brain perfusion in 467 patients undergoing hemiarch replacement. Patients with calcified aortas were excluded. They demonstrated comparable outcomes with respect to early mortality, stroke, transient ischemic attack, renal failure, and reoperation for bleeding among the three groups. Other studies comparing these three modalities for brain protection during aortic arch surgery in which the majority of patients underwent hemiarch replacement, also failed to demonstrate differences in mortality and neurologic injury. ${ }^{6-8}$ Misfeld and colleagues ${ }^{9}$ in a study of 636 patients undergoing aortic arch surgery, $71 \%$ of whom had partial arch replacement, reported comparable outcomes with regard to 30-day mortality and the occurrence of permanent and temporary neurologic deficits among patients in whom unilateral ACP, bilateral ACP, RCP, and DHCA were used for brain protection. ${ }^{9}$ Only when the two antegrade perfusion groups were combined and compared with the combined RCP and DHCA groups, a significant difference was observed in the rate of stroke ( 9 vs. $15 \%, p=0.035$ ). DHCA is the common denominator with all of these techniques, and it continues to be used as the sole form of brain protection in some centers. ${ }^{10-12}$

Although DHCA with RCP continues to be used on a routine basis for hemiarch procedures by only a minority of aortic surgeons, the outcomes at experienced aortic surgery centers where it is used have been highly satisfactory. ${ }^{13-16}$ The early mortality rate at these four centers ranged from (1.3-4.8\%). Some of the variability in early mortality is likely related to differing baseline characteristics of the patients. As an example, the percentage of patients presenting with acute Type A aortic dissection varied from 0 to $25 \%$.
Table 7 Intraoperative transfusion of blood products in 244 patients

\begin{tabular}{|l|l|l|}
\hline \multirow{2}{*}{ Blood product } & \multicolumn{2}{|l|}{ No. of units } \\
\cline { 2 - 3 } & Median & Interquartile range \\
\hline Red blood cells & 3 & $2-5$ \\
\hline Platelets & 2 & $2-3$ \\
\hline Fresh frozen plasma & 2 & $2-4$ \\
\hline Cryoprecipitate & 1 & $1-2$ \\
\hline
\end{tabular}

The rates of stroke and transient neurologic dysfunction ranged from 1.3 to 3.0 and 3.0 to $7.5 \%$, respectively, and the rate of renal failure requiring dialysis ranged from 0.3 to $2.5 \%$. The rate of reoperation for bleeding ranged from 1.3 to $4.3 \%$ RCP in these studies was delivered continuously during the period of DHCA.

In our study, RCP was delivered only at the end of the interval of DHCA, and our outcomes are comparable to those observed in the series noted above. We continue to use DHCA with RCP routinely for hemiarch procedures because of its demonstrated safety and for its simplicity, since it provides an uncluttered operative field and requires only minimal alterations in the perfusion circuit. ${ }^{3}$ We administer RCP only during the final minutes of the interval of DHCA, primarily to remove macro- and microembolic materials and air from the arterial circulation, and also to reduce the duration of brain ischemia. In addition, the availability of RCP provides an additional safety factor if the interval of DHCA has to be extended.

Concerns regarding the ability of RCP to provide meaningful suppression of cerebral metabolism and the detrimental effects of deep hypothermia (primarily increased bleeding) have led many aortic surgeons to employ ACP with moderate hypothermic circulatory arrest (MHCA; ACP + MHCA) during procedures on the aortic arch. ${ }^{2}$ Leshnower and colleagues ${ }^{17}$ performed a randomized trial comparing $\mathrm{ACP}+\mathrm{DHCA}$ with $\mathrm{RCP}+\mathrm{DHCA}$ in 20 patients undergoing hemiarch replacement (10 patients in each group). In addition to assessing the usual outcomes, they added mandatory neurologist-adjudicated preoperative and postoperative assessments and postoperative MR neuroimaging. They demonstrated a higher incidence of brain lesions consistent with acute infarction among the patients managed with ACP + MHCA (100 vs. $45 \%, p=0.01$ ). The mean number of brain lesions per patient was also significantly higher in the ACP + MHCA group $(4 \pm 3.5$ vs. $1.2 \pm 2.1 . p=0.01)$. No other significant differences in outcomes were noted between the two groups. Although the clinical significance of the silent infarcts, which are likely embolic in origin, remains unknown, the study demonstrated a lower prevalence of these lesions with DHCA and RCP.

With regard to the issue of excessive bleeding associated with DHCA, several comparative studies have failed to demonstrate significant differences in the frequency of reoperations for bleeding in patients managed with moderate or deep hypothermia. ${ }^{13,16,18-20}$ Other factors, including preoperative hemoglobin levels, emergency surgery, and the 
duration of $\mathrm{CPB}$, appear to be more important determinants of increased bleeding. ${ }^{18,21,22}$

Few studies comparing the rates of transfusion of allogeneic blood products in patients managed with deep and moderate hypothermia are available. It should be noted that $42 \%$ of the 419 patients in our series with transfusion data available received no blood products. In the large series of Girardi and colleagues, ${ }^{15}$ where RCP and DHCA were routinely used for aortic arch procedures, $49.8 \%$ of the patients undergoing hemiarch replacement required no transfusions.

\section{Limitations}

Our study was observational in nature and involved retrospective review of prospectively collected data at a single referralbased center. All procedures were performed on a single surgical service and the results may not be generalizable. However, the techniques employed are standardized and easily applicable. All of the patients did not undergo preoperative and postoperative formal neurological evaluation and the prevalence of neurologic injury may have been underestimated.

\section{Conclusion}

$\mathrm{RCP}+\mathrm{DHCA}$ with RCP delivered at the end of the DHCA interval is a safe and effective technique for brain protection for patients who require hemiarch replacement. Our study supports the findings from other studies utilizing RCP which indicated that RCP is an effective method of brain protection in this setting.

\section{Funding}

This study was supported in part by a grant from the Missouri Baptist Healthcare Foundation.

\section{Conflict of Interest}

The authors declare no conflict of interest related to this article.

\section{Acknowledgments}

None.

\section{References}

1 Ziganshin BA. Which method of cerebral protection do you prefer to use for aortic arch surgery? Aorta (Stamford) 2013;1(01):69-70

2 De Paulis R, Czerny M, Weltert L, et al; EACTS Vascular Domain Group. Current trends in cannulation and neuroprotection during surgery of the aortic arch in Europe. Eur J Cardiothorac Surg 2015; 47(05):917-923

3 Kouchoukos NT. Adjuncts to reduce the incidence of embolic brain injury during operations on the aortic arch. Ann Thorac Surg 1994;57(01):243-245

4 Hannan EL, Samadashvili Z, Cozzens K, et al. Out-of-hospital 30day deaths following cardiac surgery are often under-reported. Ann Thorac Surg 2020;110(01):183-188

5 Kaneko T, Aranki SF, Neely RC, et al. Is there a need for adjunct cerebral protection in conjunction with deep hypothermic circulatory arrest during noncomplex hemiarch surgery? J Thorac Cardiovasc Surg 2014;148(06):2911-2917
6 Svensson LG, Nadolny EM, Penney DL, et al. Prospective randomized neurocognitive and S-100 study of hypothermic circulatory arrest, retrograde brain perfusion, and antegrade brain perfusion for aortic arch operations. Ann Thorac Surg 2001;71(06): 1905-1912

7 Matalanis G, Hata M, Buxton BF. A retrospective comparative study of deep hypothermic circulatory arrest, retrograde, and antegrade cerebral perfusion in aortic arch surgery. Ann Thorac Cardiovasc Surg 2003;9(03):174-179

8 Apaydin AZ, Islamoglu F, Askar FZ, et al. Immediate clinical outcome after prolonged periods of brain protection: retrospective comparison of hypothermic circulatory arrest, retrograde, and antegrade perfusion. J Card Surg 2009;24(05):486-489

9 Misfeld M, Leontyev S, Borger MA, et al. What is the best strategy for brain protection in patients undergoing aortic arch surgery? A single center experience of 636 patients. Ann Thorac Surg 2012; 93(05):1502-1508

10 Ziganshin BA, Rajbanshi BG, Tranquilli M, Fang H, Rizzo JA, Elefteriades JA. Straight deep hypothermic circulatory arrest for cerebral protection during aortic arch surgery: safe and effective. J Thorac Cardiovasc Surg 2014;148(03):888-898, discussion 898-900

11 Elefteriades JA, Ziganshin BA. Brain protection in aortic arch surgery: antegrade cerebral perfusion and retrograde cerebral perfusion need a tougher row to hoe. J Thorac Cardiovasc Surg 2014;148(06):2902-2904

12 Schmoker J. Belt and suspenders: can we keep them in the drawer? J Thorac Cardiovasc Surg 2014;148(06):2917-2919

13 Milewski RK, Pacini D, Moser GW, et al. Retrograde and antegrade cerebral perfusion: results in short elective arch reconstructive times. Ann Thorac Surg 2010;89(05):1448-1457

14 Ganapathi AM, Hanna JM, Schechter MA, et al. Antegrade versus retrograde cerebral perfusion for hemiarch replacement with deep hypothermic circulatory arrest: does it matter? A propensity-matched analysis. J Thorac Cardiovasc Surg 2014;148(06): 2896-2902

15 Girardi LN, Shavladze N, Sedrakyan A, Neragi-Miandoab S. Safety and efficacy of retrograde cerebral perfusion as an adjunct for cerebral protection during surgery on the aortic arch. J Thorac Cardiovasc Surg 2014;148(06):2927-2933

16 Vallabhajosyula P, Jassar AS, Menon RS, et al. Moderate versus deep hypothermic circulatory arrest for elective aortic transverse hemiarch reconstruction. Ann Thorac Surg 2015;99(05): 1511-1517

17 Leshnower BG, Rangaraju S, Allen JW, Stringer AY, Gleason TG, Chen EP. Deep hypothermia with retrograde cerebral perfusion versus moderate hypothermia with antegrade cerebral perfusion for arch surgery. Ann Thorac Surg 2019;107(04):1104-1110

18 Kamiya H, Hagl C, Kropivnitskaya I, et al. The safety of moderate hypothermic lower body circulatory arrest with selective cerebral perfusion: a propensity score analysis. J Thorac Cardiovasc Surg 2007;133(02):501-509

19 Tsai JY, Pan W, Lemaire SA, et al. Moderate hypothermia during aortic arch surgery is associated with reduced risk of early mortality. J Thorac Cardiovasc Surg 2013;146(03):662-667

20 Keenan JE, Wang H, Gulack BC, et al. Does moderate hypothermia really carry less bleeding risk than deep hypothermia for circulatory arrest? A propensity-matched comparison in hemiarch replacement. J Thorac Cardiovasc Surg 2016;152(06):1559$-1569 . e 2$

21 Williams JB, Phillips-Bute B, Bhattacharya SD, et al. Predictors of massive transfusion with thoracic aortic procedures involving deep hypothermic circulatory arrest. J Thorac Cardiovasc Surg 2011;141(05):1283-1288

22 Stein LH, Rubinfeld G, Balsam LB, Ursomanno P, DeAnda A Jr. Too cold to clot? Does intraoperative hypothermia contribute to bleeding after aortic surgery?. Aorta (Stamford) 2017;5(04): 106-116 